\title{
Architecture and Functionality of a Supply Chain Enterprise Resources Planning System
}

\author{
Richard Lackes \\ Department of Business Informatics, Faculty of Business and Sociologic Sciences \\ Technische Universität Dortmund, Vogelpothsweg 87, 44227 Dortmund \\ Email: richard.lackes@tu-dortmund.de
}

\begin{abstract}
The supply chain management (SCM) aims to improve the material flow between linked enterprises by installing information systems and procedures that provide a better coordination in the logistic chain. Planning production and order quantities is a fundamental and decisive process for material flows in a supply chain. Therefore, the coordination of strategies and decisions is of great importance to the efficiency and economy of the latter. One way to improve the coordination is the construction of a central supply chain ERP system. This should complement existing ones used in diverse enterprises in order to attain better coordination of all. This way, too, the distinct scheduling systems used keep their autonomy to a large extent. Akin to "service providers," they are used by the central supply chain-oriented enterprise resources planning system (SC-ERPS), which in this respect aids an information system that loosely links different ERP systems. The required architecture, as well as the needed data and functionality are introduced and discussed here. In particular, problems related to how to handle the intersection parts in a supply chain - the parts that are produced and consumed in different enterprises of the supply chain - are analysed and solutions are discussed. These parts are physically identical but they are also different planning objects in different planning and information systems. The paper will focus on the module for the production planning process because it determines the material flow in the complete supply chain.
\end{abstract}

Keywords: enterprise resources planning, ERP, supply chain management, information system, production planning and control, coordination

\section{Introduction}

Enterprise resources planning systems are integrated business information systems that represent business objects and documents, keep records of the state of the business processes and provide data for plannig activities and decisions (Jacobs, Bendoly 2003; Ragowsky, Somen 2002; Wagner, Monk 2009). Therefore this information system reflects the state of the enterprise and its quality determines in a great extent the quality of decision making. Of course the individual ERP-systems of the independent enterprises of a supply chain contain some information about their customers and suppliers. But this information is very rough and only oriented to the needs of the enterprise itself. Hence these data is not sufficient for a supply chain management. An efficient supply chain management requires data about all enterprises in the supply chain for common planning and decision processes. Because the material flow is the decisive factor of the supply chain links a superordinate supply chain ERP-system should support the material and production planning and the respective order management (Vollmann et al 2005). 
The definition of supply chain management (SCM) covers all management activities for logistic decisions and operations inside and between independent enterprises in a supply chain. Practice and experience in recent years has demonstrated a need for supply chain management (Handfield and Nichols 1999). An integrating view throughout the entire logistics chain "from your supplier's supplier to your customer's customer" (Supply-Chain Council 2002) would present an enhanced potential for rationalization (Cooper and Ellram 1993, Cooper, Lambert, Pagh 1997; Baltacioglu et al. 2007). The whole process would benefit from greater flexibility and reduction of inefficiencies since there would be greater coordination by the participating enterprises in the value chain (Corsten and Gössinger 2001, p. 83). One important instrument for integration and coordination in single enterprises is the application of integrated information systems like ERP-systems (i.e. SAP R/3) (Balla 2006; Brehem et al. 2007). And what is useful in a single enterprise should be useful in a supply chain, too. However, the question is how it could be achieved and which modifications are necessary.

A critical point in individual ERP-systems, especially for production planning which should be improved by SCM, is the fact that production planning is largely based on forecast data that are often quite uncertain. The deviation between the future market situation and the planned market situation represented in the data of primary requirement plans causes great inefficiencies (Fleisch, Tellkamp 2005). Despite the forecast uncertainty in the future market situation represented in the data of the primary requirements plan, one must decide in using this information base about the purchase of raw materials and production of components. This is because the lead times in production and purchase are relatively long compared with the acceptable delivery times from the customer's point of view. An improvement would be early communication of all the planned data to the suppliers by a supply chain information system. In other words, a more precise view of future sales developments by early providing of planning data to other enterprises in the supply chain.

An ERP-system that supports the supply chain management in this area must be modified compared with individual ERP-systems in the following aspects: the provided data, the decision model and procedure, and the data exchange and communication between the participating enterprises.

In the following, we will discuss the architecture and procedure of such a supply chain information system. Besides the necessary features, we will discuss some possible implementation aspects and their limitations. The point of view is mainly from the perspective of information systems. And it has to be recognized that the enterprises of the supply chain are independent and have normally already their own business information systems resp. ERP-systems.

\section{Product-Oriented Architecture of a Supply Chain}

The following shall demonstrate the realisation of an SCM by providing a central information system for the purpose of coordinating the enterprises involved in the supply chain (Lackes 2004). The interface between the enterprises of a supply chain is determined by the delivered and supplied products. Therefore the entire material flow both between and inside the enterprises and the associated planning procedures and decisions have to be considered. For that reason we want to develop a formal representation of the material flow and the involved decisions for production and order planning.

First of all, a formal architecture model related to the produced and delivered products in the supply chain is designed. This structure must be reflected in the production planning process supported by the supply chain information system. The requirements for the needed data and the data interchange will be discussed.

Formalising the supply chain architecture with regard to production management interrelations requires more than just examinations on an enterprise level.

An enterprise En $(n=1, \ldots, N)$ can be defined from the perspective of their produced parts (see figure 1)

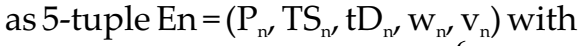

- the set of the parts $P_{n}=\left\{P_{n 1}, P_{n 2}, \ldots, P_{n M_{n}}\right\}, M_{n} \geq 1$;

- the parts structure illustrated in a gozintograph $\mathrm{TS}_{\mathrm{n}} \subseteq \mathrm{P}_{\mathrm{n}} \times \mathrm{P}_{\mathrm{n}}$ whereas $(\mathrm{x}, \mathrm{y}) \in \mathrm{TS}_{\mathrm{n}}$ means that part $x$ goes directly into part $y$; 
Figure 1. Example of a gozintograph

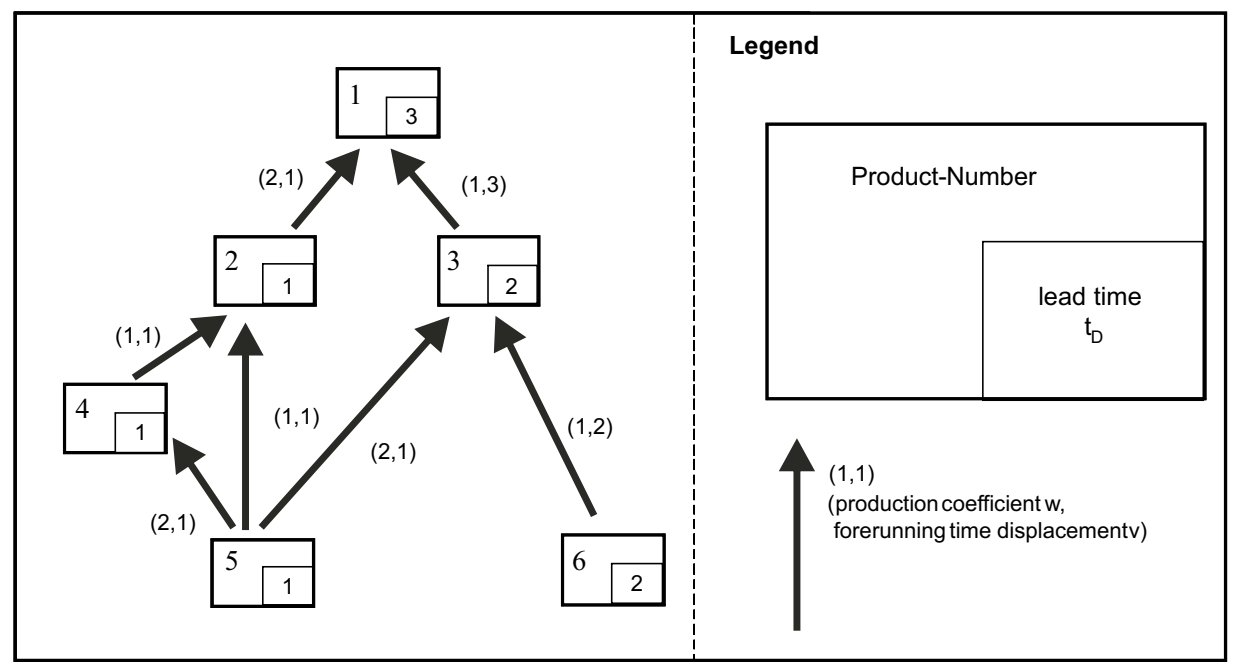

- the lead time: $\mathrm{t}_{\mathrm{Dn}}: \mathrm{P}_{\mathrm{n}} \rightarrow \mathfrak{R}_{0}^{+}$

- the production coefficient: $\mathrm{w}_{\mathrm{n}}: \mathrm{TS}_{\mathrm{n}} \rightarrow \mathfrak{R}^{+}$

- the forerunning time displacement: $\mathrm{v}_{\mathrm{n}}: \mathrm{TS}_{\mathrm{n}} \rightarrow \mathfrak{R}_{0}^{+}$

A gozintograph is used by a parts manufacturer and is typical for the industry. It is a quasi-hierarchy and therefore does not contain any cycles in the flow of material (Fandel et al 1997, Scheer 1998). This shall be assumed below. Thus, a disposition level

DS: $\mathrm{Pn} \rightarrow \mathrm{N}$ an be calculated recursively as:

$$
\begin{aligned}
& \operatorname{DS}\left(\mathrm{P}_{\mathrm{nm}}\right)= \begin{cases}0 & \text { if } \mathrm{P}_{\mathrm{nm}} \text { is a finalproduct, i.e. } \exists\left(\mathrm{P}_{\mathrm{nm}}, \mathrm{P}_{\mathrm{nm}}\right) \in \mathrm{TS}_{\mathrm{n}} \\
1+\max \left\{\mathrm{DS}\left(\mathrm{P}_{\mathrm{nm}}\right) \mid\left(\mathrm{P}_{\mathrm{nm}}, \mathrm{P}_{\mathrm{n} \tilde{\mathrm{m}}}\right) \in \mathrm{TS}_{\mathrm{n}}\right\} & \text { else }\end{cases} \\
& \text { for any } \widetilde{\mathrm{m}} \in\left\{1, \ldots, \mathrm{M}_{\mathrm{n}}\right\}
\end{aligned}
$$

The most important master data of the information system for the production and material requirements planning are the product data and the product structure data represented in the gozintograph.

The set of final products $\mathrm{EP}_{\mathrm{n}} \subseteq \mathrm{P}_{\mathrm{n}}$ covers all parts $\mathrm{P}_{\mathrm{nm}}$ with DS $\left(\mathrm{P}_{\mathrm{nm}}\right)=0$.

The set of external parts $\mathrm{FP}_{\mathrm{n}} \subseteq \mathrm{P}_{\mathrm{n}}$ covers all parts $\mathrm{P}_{\mathrm{nm}}$ implying:

$$
\nexists\left(\mathrm{P}_{\mathrm{n} \tilde{\mathrm{m}}}, \mathrm{P}_{\mathrm{nm}}\right) \in \mathrm{TS}_{\mathrm{n}} \text { for any } \tilde{\mathrm{m}} \in\left\{1, \ldots, \mathrm{M}_{\mathrm{n}}\right\}
$$

The set of final and external parts does not necessarily need to be disjunct as in e.g. commercial enterprises.
The supply relation between the enterprises is constituted by the delivery of the materials which are final products for the supplying enterprise and external parts for the enterprise supplied.

$$
\mathrm{SUP} \subseteq \bigcup_{\mathrm{n}=1}^{\mathrm{N}} E P_{\mathrm{n}} \times \bigcup_{\tilde{\mathrm{n}}=1}^{\mathrm{N}} F P_{\widetilde{n}} \text { where }\left(\mathrm{P}_{\mathrm{nm}}, \mathrm{P}_{\widetilde{\mathrm{n}} \tilde{\mathrm{m}}}\right) \in \mathrm{SUP}, \mathrm{P}_{\mathrm{nm}} \in \mathrm{P}_{\mathrm{n}}
$$
and $\mathrm{P}_{\widetilde{\mathrm{n}} \tilde{\mathrm{m}}} \in \mathrm{P}_{\tilde{\mathrm{n}}}$

with $\mathrm{n}, \tilde{\mathrm{n}} \in\{1, \ldots, \mathrm{N}\}, \mathrm{n} \neq \tilde{\mathrm{n}} ; \mathrm{m} \in\left\{1, \ldots, \mathrm{M}_{\mathrm{n}}\right\}, \tilde{\mathrm{m}} \in\left\{1, \ldots, \mathrm{M}_{\tilde{\mathrm{n}}}\right\}$

The set SUP contains the "intersection parts" in a supply chain. They are produced and consumed in different enterprises of the supply chain and therefore constitute the relationship of the enterprises in a supply chain. The intersection parts have their own "existence" and representation in the information systems within the enterprises that produce or consume them. Despite their physical identity, there are different planning objects in different planning and information systems. To improve coordination in a supply chain, they have to be particularly recognized in the production planning of a supply chain and in a supply chain ERP-system.

Figure 2 shows an example. One can see that the part 4.1 that is produced in enterprise E4 will be consumed in enterprise E1 and E2 (part 1.7 resp. 2.7). This means that part 1.7, 2.7 and 4.1 (and, of course, 3.1, too) are identical and are only planned in different 
Figure 2. Supply chain gozintograph

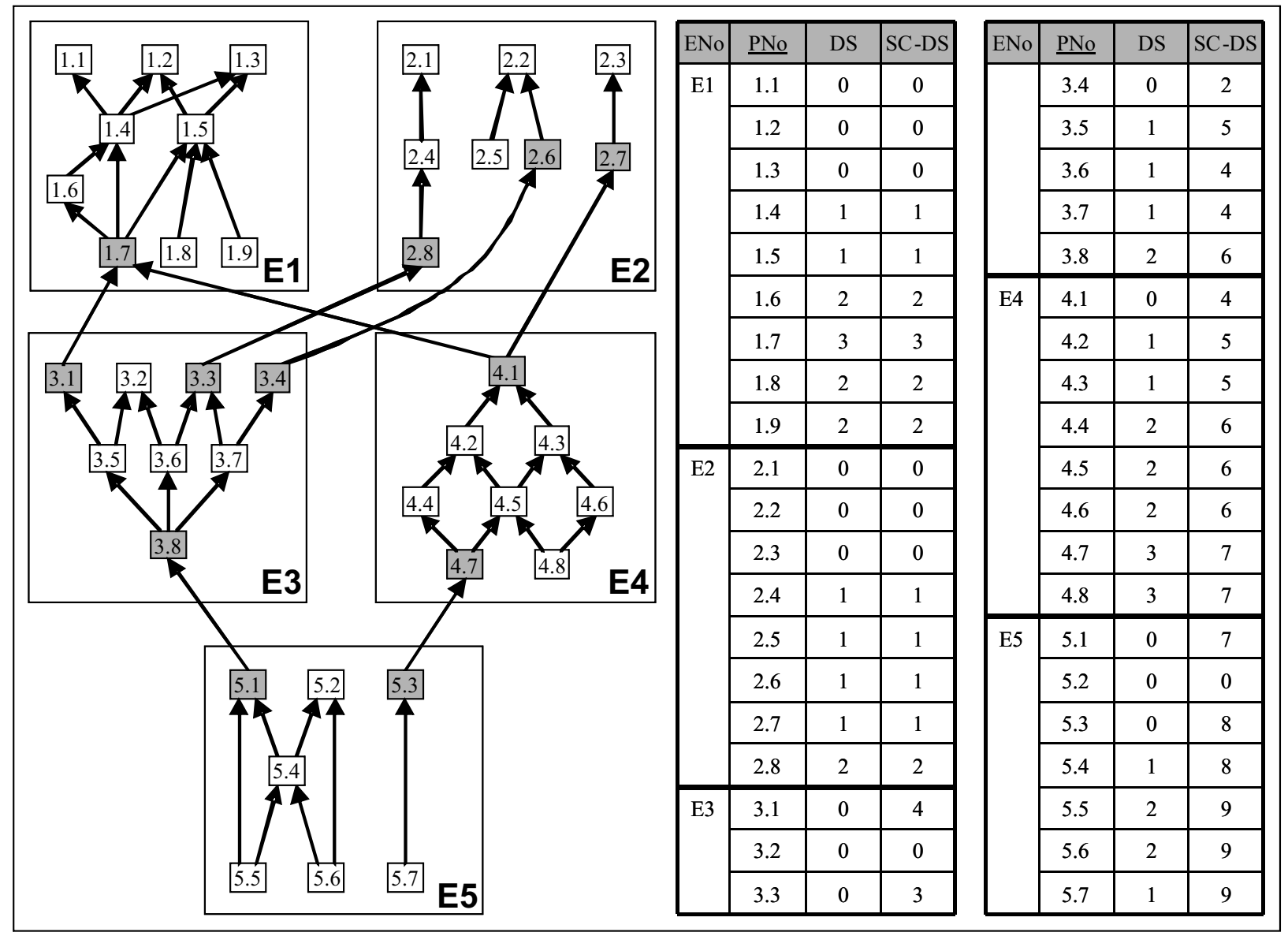

enterprises and in different individual ERP-systems. It is exactly this phenomenon which causes so many coordination problems because normally one cannot guarantee that the planning data for these intersection parts in the individual enterprises are consistent with one another.

\section{Production and Material Requirement Planning in Supply Chains}

\subsection{Supply chain gozintograph}

Let's follow the basic idea that decisions should be oriented toward the overall optimum within the supply chain (regardless of the effects on the enterprises involved). It is therefore advisable for those enterprises to improve coordination by combining the individual decentralised ERP-system into one central supply chain ERP-system. The gradual planning philosophy can be kept.

A prerequisite for supply chain production planning would be a central high-level gozintograph reflecting the constructive composition of all parts among the entire logistics chain. The intersections between the enterprises are the respective external parts of the enterprise supplied and the final products of the supplying enterprises. Fig. 2 illustrates a corresponding example.

Formally, an SC-gozintograph SC-GOZ $=(\mathrm{P} ; \mathrm{K}$; sc$\mathrm{w}$; sc-v) is obtained for the combination of all company-owned gozintographs, whereas

- P the total set of all parts: $P=\bigcup_{n=1}^{N} P$ 
- $\mathrm{K}$ the relation of the material flow:

$$
\mathrm{K}=\mathrm{U}_{\mathrm{n}=1}^{\mathrm{N}} \mathrm{TS}_{\mathrm{n}} \cup \mathrm{SUP}
$$

- $\mathrm{sc}-\mathrm{w}$ the production coefficient with sc-w : $\mathrm{K} \rightarrow \mathfrak{R}^{+}$

$\mathrm{sc}-\mathrm{w}(\mathrm{k})=\left\{\begin{array}{l}\alpha(\mathrm{k}) \text { if } \mathrm{k} \in \mathrm{SUP} \\ \mathrm{w}(\mathrm{k}) \text { if } \mathrm{k} \notin \mathrm{SUP}\end{array}\right.$

where $\alpha=$ SUP $\rightarrow$ ]0.1] is the share of a bought-in part on the total required quantity of customer;

$\alpha\left(P_{n m}, P_{\tilde{n} \tilde{m}}\right)=1$ if $E_{n}$ is sole supplier to enterprise with regard to product $P_{n m}$.

$\mathrm{sc}-\mathrm{v}$ represents the forerunning time displacement

$\mathrm{sc}-\mathrm{v}: \mathrm{K} \rightarrow \mathfrak{R}^{+}$with

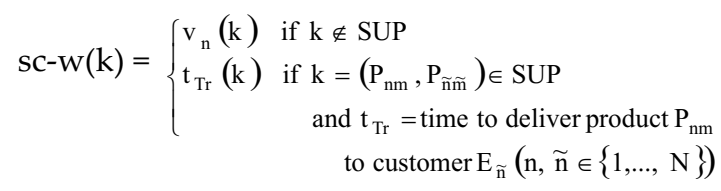

The set of nodes of the SC-gozintograph is gained from the total set of nodes of all individual gozintographs representing the respective parts. Therefore, the intersection parts are multiplied and represented in different nodes. The connections of the material flow combine the individual gozintographs by their material supply relationship.

At the intersections between the enterprises linked together in the supply chain, new production coefficients have to be generated. They correspond to the share of the quantity of an order of the product in question which belongs to the supplier considered. If there are further suppliers outside the supply chain, the sum of those "production coefficients" does not have to add up to 1 . A dynamically changing "production coefficient" illustrating the respective order strategy is certainly also possible. It is not a question of a technically determined factor but rather one that is economically determined. The forerunning time displacement $\mathrm{sc}-\mathrm{v}$ at the newly created intersection edges corresponds to the concerned product's transportation time between supplier and customer. In a decentralised system, the agreed delivery time is used for a definite order on the part of the customer. However, in this case the time of the order is irrelevant. What is important is the latest time the finished product must be available. Therefore, the forerunning time displacement can only be the transportation time.

Let's concentrate on non-cyclical structures of the material flow, since they are typical for the industry such that even the SC-gozintograph is quasihierarchical in the supply chain. The SC-disposition levels being used as criteria for the sequence of the material requirement planning are calculated as follows:

$$
\begin{gathered}
\mathrm{SC}-\mathrm{DS}\left(\mathrm{P}_{\mathrm{nm}}\right)=\left\{\begin{array}{l}
0 \quad \text { if } \mathrm{P}_{\mathrm{nm}} \in \mathrm{EP}_{\mathrm{n}} \text { and } \exists\left(\mathrm{P}_{\mathrm{nm}}, \mathrm{P}_{\tilde{\mathrm{n}}}\right) \in \mathrm{SUP} \\
1+\max \left\{\mathrm{SC}-\mathrm{DS}\left(\mathrm{P}_{\widetilde{\mathrm{n}} \tilde{m}}\right) \mid\left(\mathrm{P}_{\mathrm{nm}}, \mathrm{P}_{\widetilde{\mathrm{n}} \tilde{\mathrm{m}}}\right) \in \mathrm{K}\right\} \text { else }
\end{array}\right. \\
\text { for any } \widetilde{\mathrm{n}} \in\{1, \ldots, N\} \widetilde{\mathrm{m}} \in\left\{1, \ldots, \mathrm{M}_{\widetilde{\mathrm{n}}}\right\}
\end{gathered}
$$

\subsection{Planning procedure and modifications}

According to the sequence dictated by the SC-DS, the material requirements calculation starting at level 0 would be carried out at the final products of the entire supply chain. The necessary data is to be found for most of the parts in the local information systems of the involved enterprises. The data are stored in the central information system for only the intersection products.

The algorithm for the material requirement calculation, with a gross-net calculation and lot-sizing, is affected by modifications in the following aspects:

- Primary requirement planning

- Different lengths of sub-periods in the plans

- Relevant planning horizon

- Treatment of the intersection products

\subsubsection{Primary requirement planning}

The starting point of the material requirement calculation is the data of the primary requirement plan which is set up for the marketable products. When considered individually, these are the final products and the marketable semi-finished products of the individual enterprises. This means slight modifications for the production planning of a supply chain. 
Final products of the supply chain are only those products Pnm with SC-DS $\left(\mathrm{P}_{\mathrm{nm}}\right)=0 ; \mathrm{n} \in\{1, \ldots, \mathrm{N}\}$; $\mathrm{m} \hat{\imath}\{1, \ldots, \mathrm{M}\}$. These are the final products which are at the very end of the material flow of the entire supply chain. The customers for these products are therefore not administered within the supply chain. The original final products of the supply chain enterprises being delivered to other members of the supply chain fail, in the view of the supply chain, to be final products. They are "internal" products for the supply chain resp. internal nodes of the SC-gozintograph and no longer need a primary requirement plan. Their requirement data will be obtained by the planned orders of the enterprises that are delivered by these products.

If all customers are members of the supply chain, the secondary requirement resulting from the supply of the customer replaces the original locally planned primary requirement for these products. If there is additional customer demand for this product outside the supply chain, it corresponds to the character of a marketable semi-finished product in the view of the individual enterprise. In that case, external sales for these products must be planned separately as an individual primary requirement. For the concrete procedure to handle these parts, see the discussion about intermediate parts below.

A similar phenomenon in the opposite direction can be found in the parts not entirely to be obtained from suppliers within the supply chain. They are therefore, from the point of view of the supply chain, internal parts as well as bought-in parts. This must be considered separately for lot-sizing within the material requirements disposition.

\subsubsection{Different length of sub-periods in the plans}

Although it would be certainly most convenient for a SC-ERP to insist that all companies involved should use the same unit of period break-down, one will mostly find, for autonomy reasons, differently structured units of sub periods in their production plans. Therefore, a transformation of the customer's planning data must be made according to his unit of period break-down into the unit of period break-down of the supplier at transitions between the enterprises linked directly within the material flow of the supply chain. If the supplier's screening is finer, the highest flexibility is secured by assigning the amounts to the last sub-period which is still completely in the subperiod of the period break-down of the customer. If the screening is rather rough, we have an aggregation.

\subsubsection{The necessary planning horizon}

The necessary planning horizon is dependant on the total lead time in the entire supply chain and the typical range of orders (Lackes 1994). The longer the planning horizon is, the more uncertain, in general terms, the data of the primary requirement becomes. This effect will be intensified by dynamically changing markets. That is a very critical point for supply chain production planning. The relevant planning horizon of a supply chain will be - under the same conditions much larger than in an individual single scan as is inter alia the lead time of the complete material flow in the supply chain that needs to be considered.

There will be enterprises in the supply chain that have had more valid forecasted sales than they needed for their own individually relevant planning horizon but abstained to integrate the data into the primary requirement plan for cost reasons. For those, the demand to provide data for a longer planning horizon will not be critical. It will be harder for the companies with a more dynamic market, as this represents more difficulties for estimations over a longer period. Depending on the decrease of the reliability of the forecasted sales with a growing planning horizon, the dispositions' quality in the supply chain and therefore the convenience of an SCM will decrease as well. Here, we find hard restrictions for the possible improvements by even sophisticated supply chain management.

\subsubsection{Treatment of the intersection parts}

Because of their special and decisive character in the supply chain, the intersection parts as defined above have to be treated separately. If the material requirement disposition for part $\mathrm{P}_{\mathrm{nm}} \in \mathrm{FP}_{\mathrm{n}}$ obtained from at least one supplier of the supply chain (i.e. $\left(\mathrm{P}_{\tilde{\text { ñm }}}\right.$. $\left.P_{n m}\right) \in S U P$ for at least one part $P_{\tilde{n} \tilde{m}} \in E_{n}$ ) is carried out, the hereby implied demand for requirements explosion is to be calculated after the lot-sizing for all bought-in parts concerned.

An example-as shown in figure 3 - will demonstrate the procedure in the "traditional" and in 
Figure 3. Example of the treatment of intersection parts
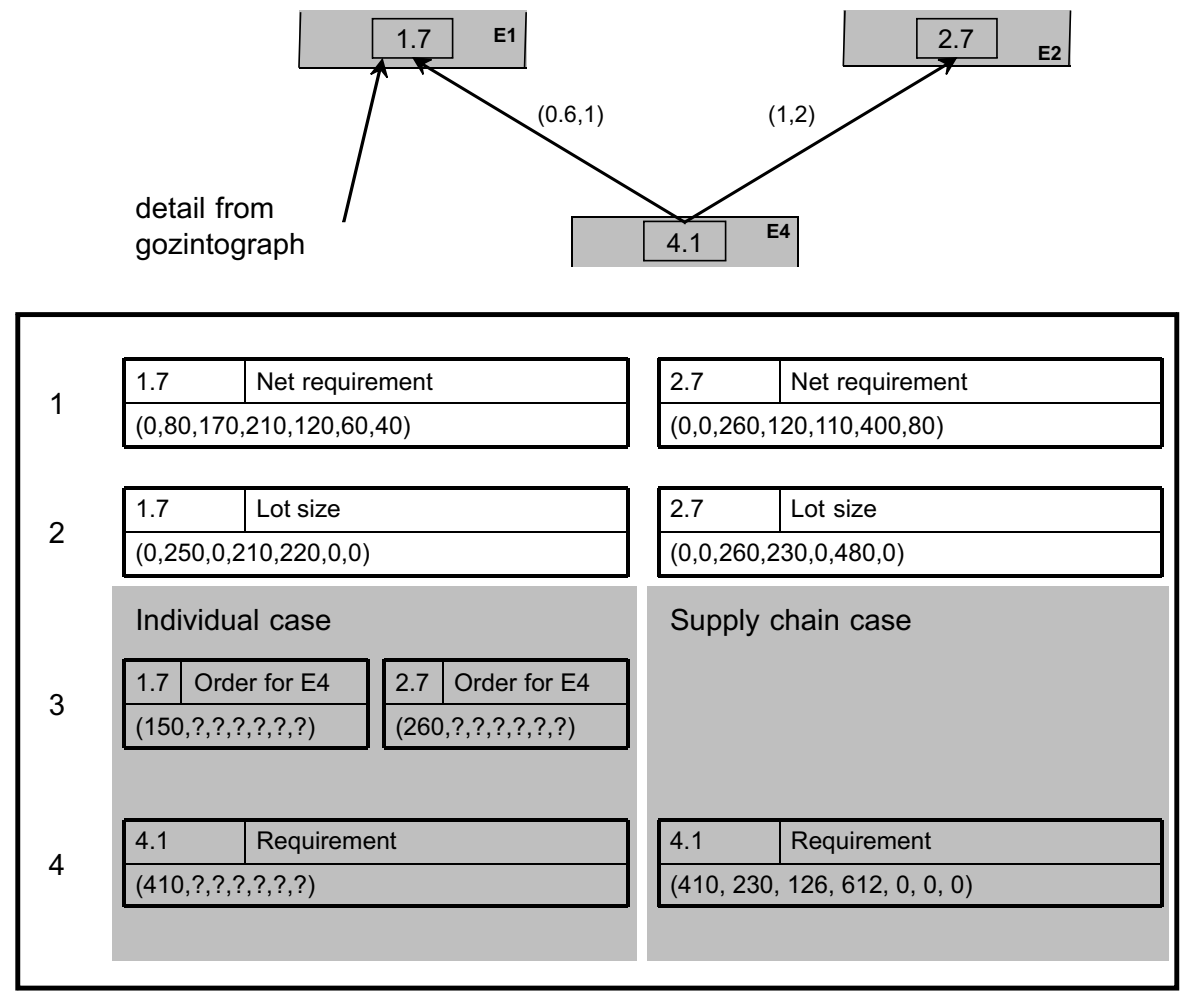

the supply chain case. Let's look at a cut-out of the supply gozintograph in figure 2 , with the parts 1.7, 2.7, and 4.1 of the supplied enterprises E1 and E2 and the delivering enterprise E4. Remember that 1.7, 2.7., 4.1 and of course 3.1 are the same products. They exist only as different planning objects in different enterprises and different information systems.

In the first step, the net requirement of parts 1.7 and 2.7 are calculated for the entire planning horizon. In the second step, each enterprise calculates its optimal lot-sizes resp. order sizes according to its cost data for storage (variable costs) and procurement (fixed costs).

Considering the forerunning time displacement sc- $\mathrm{v}$ and the production coefficient sc $\mathrm{W}\left(\mathrm{P}_{\tilde{\mathrm{n}} \tilde{m}}, \mathrm{P}_{\mathrm{nm}}\right)$ (i.e. it may be sc-v $(4.1,1.7)=1, \mathrm{sc}-\mathrm{v}(4.1,2.7)=2$; sc$\mathrm{w}(4.1,1.7)=0.6$, sc- $\mathrm{w}(4.1,2.7)=1)$, the order quantity that is sent to the supplier in the third step will be determined. In this example, the supplier gets only the order data of 150 units from E1 and 260 units from E2, for a total of 410 units. The missing values for his production and material planning within his planning horizon must be estimated or forecasted.

One improvement in supply chain environments compared with the individual procedure would be to inform the supplier about the planned orders in the future (Fiala 2005, Lackes 2008). This communicated forecast data can support the supplier's disposition considerably and reduce the bullwhip effect (Bayraktar et al. 2008; Chatfield et al. 2004; Chen et al. 2000; Lackes and Siepermann 2007; Lee et al. 1997).

But there is another weak point that could be improved by supply chain management: The successive double lot-sizing (initially with the customer and secondly with the supplier) restricts the supplier's flexibility and singly discriminates his position. Therefore, I would suggest that in supply chain ERP, the lot-sizing of intersection parts should be done simultaneously. Because it always concerns only two stages in the material flow, one can use optimizing algorithms for this function with the objective to minimize the total costs that are relevant for the lotsizing of the intersection parts (Afentaktis, Gavish 1986; Kimms 1997; Maes et al. 1991). 
The result will be feasible and coordinated order plans of the intersection parts for all involved enterprises (suppliers and supplied enterprises) that lead to minimal total cost. Of course, this suggestion could impair the individual cost situation of supplied enterprises because there may be deviations from their minimal cost-purchasing batches. For that reason, there should be a compensation of the concerned enterprises by a suitable allocation of the benefits caused by the simultaneous optimization between all involved enterprises. The data for that can be administrated in the supply chain ERP-system and can also be integrated into a supply chain controlling module.

An additional aspect in the treatment of intersection parts that has to be considered is that suppliers external to the supply chain could deliver a portion of the order. In this case, a respective plan of procurement orders must be made out. Only the supply within the supply chain is treated like a production order. In addition, it needs to be considered for those parts that an individual primary requirement can be included into the planning if there are also customers outside the supply chain.

\section{Implementation of SC-ERP Systems}

To realize the described procedure of production planning in a supply chain ERP-system, there can be two distinct alternatives of implementation:

1. Substitution of the local ERP-systems of the individual enterprises by a globally centralized supply chain ERP-system (see figure 4);

2. An add-on to the local ERP-systems by a central SC-ERP information system with well-defined limited supporting functions (“virtual ERP-system").

\subsection{Substitution of local ERPs by global SC-ERP}

Although the suggestion to constitute a unique common global ERP-system for every enterprise of the supply chain instead of their own local ERP-systems
Figure 4. Centralized SC-ERP-system

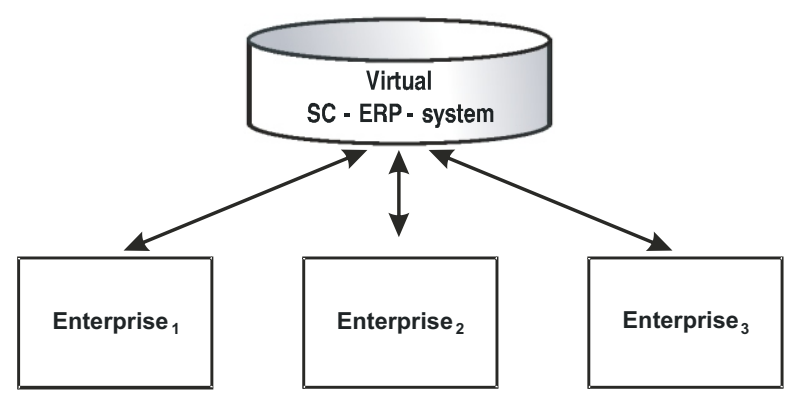

would have the advantages of a complete integration and standardization of all data and procedures, it will be almost impossible to achieve.

There are a lot of important arguments against such an extreme solution. First, it has to be taken into account that there are already well-established local information systems that are customized to individual needs. A global information system could surely not be adopted in the same way to the individual demands and features. Secondly, apart from business partners within the supply chain, external customers and suppliers of every enterprise of the supply chains have to be considered as well.

And thirdly, one should not forget that normally the enterprises are not only integrated in one supply chain but in several supply chains. Which global supply chain ERP-system should then be used? This argument emphasizes the meaning of one's own autonomy. The waiving of one's own information system would be a too extensive abandonment of autonomy. This cannot be expected. As a consequence, the first alternative of implementation of an SC ERP will fail in most cases.

\subsection{Add-on to local ERPs by a "virtual" SC-ERP}

The second alternative to implementing the ideas of supply chain ERP consists of an add-on solution to the local ERPs (s. figure 5). Only special data areas and functions are swapped to the global SC-ERP, which works like a superordinate, "virtual" ERP system. It could be achieved as a supply chain portal that: 
Figure 5. Virtual SC-ERP as add-on solution

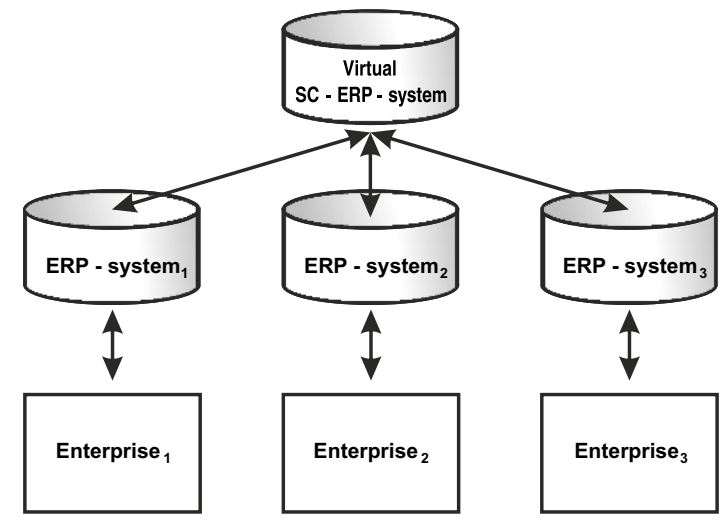

- controls the material and information flow only between and not inside the enterprises of the supply chain;

- determines some basic conditions and rules for the local individual planning;

- supports the necessary data interchange;

- uses the local ERP-systems as "services" similiar to SOA-concepts (Singh, Huhns 2005).

Especially the administration of the relevant data for planning the intersection parts (e.g. the identification of the corresponding part numbers, the production coefficient, the forerunning time displacement, the supply chain disposition level, perhaps even the inventory) and the transformation service for converting the different measurement of products (e.g. customer 1: pallets, customer 2: tons, supplier: per item) and different planning period breakdowns are tasks of the global information system. The order planning and lot-sizing of the intersection parts - but based on the net requirement data provided by the delivered enterprises and the cost data provided by the involved enterprises - will be executed by the SC-ERP. Furthermore, it can take over the collection of controlling data relevant for the whole supply chain in order to identify weak points and to allocate the benefits of the supply chain to the involved enterprises.

It would be ideal for the master plan of the supply chain if the material requirement planning was carried out synchronically. However, a standardized clocking of the planning moves may often be difficult to achieve due to individual internal specifications. Therefore, both alternatives - synchronous and asynchronous processing-are conceivable.

A synchronous planning process for all enterprises of the supply chain will be started by the virtual SC-ERP that triggers and controls the procedure. In the first step, the primary requirement data for the necessary planning horizon have to be determined by the responsible enterprises. That concerns all parts/products of the supply chain that are on supply chain disposition level 0 . Furthermore, the parts with customers outside the supply chain need data about the forecasted sales within the planning horizon., The local ERP-systems are responsible for determining these primary requirement data. The "virtual" SC-ERP triggers only the beginning of this process for the relevant products.

In the next step, the local ERP-systems of each enterprise of the supply chain that produces at least one product on SC-disposition level 0 have to call their inherent planning algorithms to determine the gross and net requirement of all internal parts and to calculate the lot sizes of all internal parts besides the intersection parts. From the perspective of the virtual SC-ERP, this procedure works like a black box (therefore, one could divide the supply chain gozintograph in planning sections controlled by the local ERP-system and one controlled by the global ERP-system).

For the intersection parts, the net requirement data will be sent to the virtual SC-ERP that processes a 2-stage lot size optimization. For this reason, besides the net requirement data of the intersection parts the relevant cost data, such as storage costs, purchase and delivery fixed costs have to be stored in the global information system.

The result will be an order plan for the intersection parts that will be consumed in the supplied enterprise and will be produced in the supplying enterprise. Different lengths of the subperiods used by the involved enterprises are recognized by suitable transformations. And, of course, the sequence of the procedure of the entire production planning goes strictly by ascending supply chain disposition level. 


\section{Conclusion}

With the formal model of the supply chain material flow it was shown that a great deal of the coordination problems is caused by the sovereign logistics decisions of the involved enterprises, that are based on individual objectives. These affect both the internal production and order plans as well as the procurement contracts in regard to the suppliers. The basis of their respective dispositions is the data in their enterprise ERP system. A better coordination of material flows requires a greater exchange of information "information is the essential ingredient for a successful supply chain management" (Lee et al. 1997) - and the bounded transfer of planning functions in an superordinate supply chain ERP system.

A concept for achieving, that the coordination function supports the supply chain management, is the virtual supply chain ERP-system as described above. This global business information system combines existing local ERP-systems of the involved enterprises in a supply chain to get a higher degree of coordination for planning and decision. It is organized like a portal solution that envelopes the local ERP-systems and triggers the planning functions as services for the supply chain production planning.

It is important that the individual ERP systems of the various supply chain enterprises are preserved, and autonomy just on a limited scale is handed to the SCERP system. Thereof affected are solely those products (intersection parts), that are supplied among the SCenterprises. The provision of relevant planning data (medium-term order plans, planning periods, supply ratio, stocks, etc.) and the execution of the order plan for the intersection parts significantly improve the coordination within the supply chain. Of course the availability and quality of information about the product's sales market at the end of the supply chain remain a critical factor for its success.

Some further aspects should still be examined more intensively in future projects. Besides the technical interface realization in-between different ERP systems, the organization of the planning processes for the entire supply chain in particular may be problematic. It would be ideal if the processes could be executed almost synchronously. If this can not be implemented due to different general conditions in the different enterprises, an alternative concept of the planning organization must be developed. The required renunciation of autonomy as to the planning of the intersection parts will improve the coordination for the entire supply chain, but may lead to a change for the worse in some corporations that needs to be compensated. Furthermore, an allocation method for the gained coordination profit should be developed that is accepted by all supply chain stakeholders.

\section{References}

Afentakis, P. and Gavish,P. (1986). Optimal Lotsizing Algorithms for complex product structures. Operations Research, 34, pp. 237-249.

Balla, J. (2006). Production Planning with SAP APO-PP/DS, Bonn.

Baltacioglu, T., Ada, E., Kaplan, M.D., Yurt, O. and Kaplan, Y.C. (2007). A New Framework for Service Supply Chains. The Service Industries Journal, 27, pp. 105-124.

Brehm, N., Marx Gomez, J. and Rautenstrauch, C. (2007). An ERP Solution Based on Web Services and Peer-to-Peer Networks. International Journal of Information Technology and Management, 1.pp.99-111.

Bayraktar, E., Koh, L., Gunasekaran, A., Sari, K. and Tatoglu; E. (2008). The role of forecasting on bullwhip effect for ESCM applications. International Journal of Production Economics, 113 (1), pp. 193-204.

Chatfield, D.C., Kim, J.P., Harrison, T.P. and Hayya, J.C. (2004). The Bullwhip Effect - Impact of Stochastic Lead Time, Information Quality and Information Sharing: A Simulation Study. Production and Operations Management, 13 (4), pp. 340-353.

Chen, F., Drezner, J., Ryan, J.K. and Simchi-Levi, D. (2000). Quantifying the Bullwhip Effect in a Simple Supply Chain: The Impact of Forecasting, Lead Times, and Information. Management Science, 46 (3), pp. 436-443.

Cooper, J. and Ellram, L.M. (1993) Characteristics of Supply Chain Management and the Implications for the Purchasing and Logistics Strategy. The International Journal of Logistics Management, 4(2), pp. 13-24.

Cooper, M.C., Lambert, D.M. and Pagh, J.D. (1997). Supply Chain Management: More Than a New Name for Logistics. The International Journal of Logistics Management, 8 (1), pp.1-14.

Corsten, H. and Gössinger R. (2001). Einführung in das Supply Chain Management, Oldenbourg, München, Wien.

Dyckhoff, H., Lackes, R. and Reese, J. (2004). Supply Chain Management and Reverse Logistics, Springer, Berlin. 
Fandel, G., François, P. and Gubitz, K.-M. (1997). PPS- und integrierte betriebliche Softwaresysteme: Grundlagen Methoden-Marktanalyse, Springer Verlag, $2^{\text {nd }}$ edn. Berlin.

Fiala, P. (2005). Information Sharing in Supply Chains. Omega: the International Journal of Management Science, 3(2), pp. 13-24

Fleisch, E., Tellkamp, C. (2005). Inventory Inaccuracy and Supply Chain Performance: A simulation study of a Retail Supply Chain. International Journal of Production Economics, 95, pp.373-385.

Handfield, R.B. and Nichols, E.L. (1999). Introduction to Supply Chain Management, Prentice Hall, Upper Saddle River NJ.

Jacobs, F.R. and Bendoly, E. (2003). Enterprise resource planning: developments and directions for operations management research, European Journal of Operational Research, 146, pp. 233 - 240.

Kimms, A. (1997). A multi-Level Lot Sizing and Scheduling, Springer-Verlag, Heidelberg.Lackes, R. (1994). Just-intime Produktion: Systemarchitektur - wissensbasierte Planungsunterstützung - Informationssysteme, Gabler, Wiesbaden.
Lackes, R. (2004). Information System for Supporting Supply Chain Management, in: Dyckhoff, H., Lackes, R. and Reese, J. (Eds), Supply Chain Management and Reverse Logistics (Berlin: Springer), pp. 405-426.

Lackes, R. (2008). Informationsbereitstellung zur Koordination in supply chains - Eine kritische Analyse, in: Ivanov, D.; Jahns, C.; Straube, F.; Procenko, O.; Sergeev, V. (Eds), Logistics and Supply Chain Management: Trends in Germany and Russia. St. Petersburg.

Lackes, R. and Siepermann, M. (2007). Aspects of Risk Reduction concerning Forecast Data in CustomerSupplier Relationships. In: Pawar, K. S.; Lalwani, C. S.; Muffatto, M. (Hrsg.): Proceedings of the 12th International Symposium on Logistics (ISL 2007), Nottingham, pp. 179185.

Richard Lackes is full professor in the Department of Business Informatics, Faculty of Business and Sociologic Sciences, Technische Universität Dortmund, Germany. He studied computer science and business administration at the University of Saarland, and received a Ph.D. in business administration and business informatics. His teaching and research interests include business information systems, supply chain management, logistics and applied operations research. His email address is <Richard.Lackes@tu-dortmund.de $>$ 